\title{
GAMBARAN PELAKSANAAN INISIASI MENYUSUI DINI (IMD)
}

\author{
Safrina ${ }^{l}$,Tengku Sri Wahyun ${ }^{2} i$ \\ ${ }^{12}$ Poltekkes Kemenkes Medan \\ email : 'daulaysafrina@gmail.com
}

\begin{abstract}
The World Health Organization (WHO) and the United Nations Children's Fund (UNICEF) have recommended that children start breastfeeding within the first hour after birth and be exclusively breastfed for the first six months of life (no food or other fluids are given)., including water) (UNICEF \& WHO, 2018). An estimated 78 million babies - or three in five babies - are not breastfed in the first hour of life. This puts them at a higher risk of death and disease and makes them less likely to continue breastfeeding (World Health Organization, 2018a). Data from WHO shows that only $40 \%$ of infants have received early initiation of breastfeeding (IMD). WHO itself targets that by $203070 \%$ of infants have received early initiation of breastfeeding (WHO \& UNICEF, 2018). The type of research used is descriptive, namely research that clearly describes the variables studied without doing statistical tests. This research was conducted at BPM Pematangsiantar City. The study was conducted in March 2021 with a sample size of 29 people. The sampling method in this study was non-probability sampling, namely by consecutive sampling. The description of the IMD implementation shows that the majority of respondents are aged 20-35 years (65.5\%) and the least is <20 years old (6.9), the highest parity is 3 (34.5\%) and the least parity is 5 (6.9\%). ), all respondents gave birth at term pregnancy (100\%), and all respondents did early initiation of breastfeeding (100\%) while the implementation of IMD was mostly carried out immediately after birth (89.7\%) and the longest IMD implementation was between 30 minutes to 30 minutes. $d 1$ hour (69\%) but there are also those who carry out IMD less than 30 minutes (10.3\%). Type of Research Analytical survey with cross sectional design. It is hoped that health workers will carry out an IMD in every delivery immediately after the baby is born and the need for husband and family support in accompanying the delivery process in carrying out IMD.
\end{abstract}

Keywords: Maternity; Early Initiation of Breastfeeding (IMD).

\begin{abstract}
ABSTRAK
Organisasi Kesehatan Dunia (WHO) dan Dana Anak-anak Perserikatan Bangsa-Bangsa (UNICEF) telah merekomendasikan agar anak-anak mulai menyusu dalam satu jam pertama setelah lahir dan disusui secara eksklusif selama enam bulan pertama kehidupan (tidak ada makanan atau cairan lain yang diberikan, termasuk air) (UNICEF \& WHO, 2018). Diperkirakan 78 juta bayi - atau tiga dari lima bayi - tidak disusui dalam satu jam pertama kehidupan. Hal ini menempatkan mereka pada risiko kematian dan penyakit yang lebih tinggi dan membuat mereka cenderung tidak melanjutkan menyusui (World Health Organization, 2018a). Data dari WHO menunjukkan baru 40\% bayi yang telah menerima inisiasi menyusu dini (IMD). WHO sendiri menargetkan pada tahun 2030 sebesar $70 \%$ bayi telah menerima inisiasi menyusu dini (WHO \& UNICEF, 2018).. Tujuan penelitian untuk mengetahui Untuk mengetahui gambaran pelaksanaan IMD di kota Pematangsiantar. Jenis penelitian yang digunakan deskriptif yaitu penelitian yang menggambarkan secara jelas variable yang diteliti tanpa melakukan uji statistic. Penelitian ini dilakukan di BPM Kota Pematangsiantar. Penelitian dilaksanakan pada bulan Maret 2021 dengan besar sampel 29 orang dengan cara pengambilan sampel dalam penelitian dilakukan dengan non probability sampling yaitu dengan cara consecutive sampling. Gambaran pelaksanaan IMD bahwa responden terbanyak berumur 20-35 tahun (65,5\%) dan paling sedikit umur $<20$ tahun $(6,9)$, paritas terbanyak adalah $3(34,5 \%)$ dan paling sedikit paritas $5(6,9 \%)$, semua responden melahirkan pada kehamilan aterm (100\%), dan semua responden melakukan inisiasi menyusu dini (100\%) sedangkan dalam pelaksanaan IMD paling banyak dilakukan segera setelah lahir $(89,7 \%)$ dan lama pelaksanaan IMD terbanyak antara 30 menit s/d 1 jam (69\%) namun ada juga yang melaksanakan IMD kurang dari 30 menit (10,3\%). Jenis Penelitian Survey analitik dengan desain cross sectional. Diharapkan kepada petugas kesehatan agar di setiap persalinan dilakukan IMD segera setelah bayi lahir dan Perlunya dukungan suami dan keluarga dalam mendampingi proses persalinan dalam melakukan IMD.
\end{abstract}

Kata kunci: Ibu bersalin;Inisiasi Menyusui DINI (IMD). 


\section{PENDAHULUAN}

Organisasi Kesehatan Dunia (WHO) dan Dana Anak-anak Perserikatan Bangsa-Bangsa (UNICEF) telah merekomendasikan agar anak-anak mulai menyusu dalam satu jam pertama setelah lahir dan disusui secara eksklusif selama enam bulan pertama kehidupan (tidak ada makanan atau cairan lain yang diberikan, termasuk air) (UNICEF \& WHO, 2018). Diperkirakan 78 juta bayi - atau tiga dari lima bayi - tidak disusui dalam satu jam pertama kehidupan. Hal ini menempatkan mereka pada risiko kematian dan penyakit yang lebih tinggi dan membuat mereka cenderung tidak melanjutkan menyusui (World Health Organization, 2018a). Data dari WHO menunjukkan baru $40 \%$ bayi yang telah menerima inisiasi menyusu dini (IMD). WHO sendiri menargetkan pada tahun 2030 sebesar $70 \%$ bayi telah menerima inisiasi menyusu dini (WHO \& UNICEF, 2018). Berdasarkan Riset Kesehatan Dasar 2018, proporsi IMD tingkat nasional adalah 58,2\%. Meskipun hal ini telah berada di atas capaian WHO tetapi proporsi IMD di propinsi Sumatera Utara merupakan ranking ketiga terendah setelah Papua Barat dan Maluku yaitu 39,9\% (Badan Penelitian dan Pengembangan, 2019).

Berbagai literatur menunjukkan hubungan IMD dengan kematian dan kesakitan bayi. Hasil penelitian Smith et al (2017) mendapati hubungan waktu mulai menyusui dengan angka kematian bayi. Peningkatan penundaan waktu mulai menyusui dikaitkan dengan peningkatan risiko kematian neonatal. Bayi yang mulai menyusu 2-23 jam setelah lahir memiliki risiko kematian neonatal $33 \%$ lebih besar dan bayi yang mulai menyusu 24 jam setelah lahir memiliki risiko dua kali lebih besar untuk meninggal selama periode neonatal jika dibandingkan dengan mereka yang mulai menyusu dalam waktu satu jam setelah lahir (Smith et al., 2017). Selain itu juga didapati hubungan antara inisiasi menyusu dini dan morbiditas (misalnya diare, infeksi saluran pernapasan, hipotermia, dan infeksi tali pusat) (Smith et al., 2017). Dalam sebuah penelitian terhadap lebih dari 4.000 anak di Tanzania, penundaan inisiasi menyusu dikaitkan dengan peningkatan risiko batuk dan hampir 50 persen peningkatan risiko kesulitan bernapas dalam enam bulan pertama kehidupan, dibandingkan dengan bayi baru lahir yang mulai menyusui dalam waktu singkat jam pertama kelahiran (UNICEF \& WHO, 2018).

Pemerintah Indonesia telah menetapkan berbagai program untuk mendukung keberhasilan IMD diantaranya adalah program rumah sakit sayang ibu dan bayi (Menteri Kesehatan Republik Indonesia, 2008) dan sepuluh langkah keberhasilan menyusui yang ditetapkan oleh Menteri Pemberdayaan Perempuan \& Perlindungan Anak (Menteri Negara Pemberdayaan Perempuan \& Perlindungan Anak Republik Indonesia, 2010). Selain itu WHO telah memberikan rekomendasi kepada tenaga kesehatan agar melakukan konseling menyusui saat prenatal, postnatal, dan selama 24 bulan atau lebih. Konseling ini sedikitnya dilakukan selama enam kali, melalui tatap muka langsung, telepon, atau media lain (World Health Organization, 2018b).

Pengetahuan ibu yang rendah tentang IMD, tingkat pendidikan ibu, dukungan tenaga kesehatan dan keluarga, konseling menyusui yang belum berjalan dengan baik, cara bersalin, dan tempat melahirkan adalah beberapa faktor yang menghambat pelaksanaan IMD (Sinaga \& Siregar, 2020) (Novianti, Mujiati, 2019) (Swandy. et al., 2019). Hasil penelitian Lestariningsih (2016) di ruang bersalin mendapati bahwa tidak semua pasien mendapatkan informasi dari tenaga kesehatan tentang IMD sebelum melahirkan. Penyuluhan yang diberikan tenaga kesehatan pada pasien inpartu biasanya dilihat terlebih dahulu pada kondisi ibu yang akan melahirkan, jika masih kooperatif penyuluhan pertama yang diberikan adalah tentang proses persalinan atau tehnik mengedan (Lestariningsih, 2016). Penelitian Damayanti (2016) menemukan bahwa pelaksanaan IMD belum maksimal masih sebesar 60\% dilakukan oleh semua bidan (Damayanti, 2016).

Survei awal pada beberapa ibu postpartum di praktek mandiri bidan menyatakan bayinya diletakkan di atas perut hanya sebentar lebih kurang sepuluh menit. Saat observasi, beberapa bidan yang menolong persalinan juga meletakkan bayi di atas perut ibu hanya sekitar sepuluh sampai lima belas menit. Berdasarkan uraian di atas, penulis tertarik untuk melakukan penelitian tentang gambaran pelaksanaan IMD di Kota Pematangsiantar.

\section{TUJUAN}

Untuk mengetahui gambaran pelaksanaan IMD di kota Pematangsiantar

\section{MANFAAT}

1. Sebagai bahan masukan kepada Dinas Kesehatan Kota Pematangsiantar untuk merencanakan kegiatan-kegiatan yang mendukung kesehatan ibu bersalin tentang pelaksanaan pemberian ASI eksklusf.

2. Sebagai pelengkap bahan acuan ilmiah dalam mengembangkan pengetahuan dan peningkatan kesehatan bagi masyarakat umumnya dan ibu bersalin sesuai dengan evidence based.

\section{METODE}

Penelitian dilaksanakan pada bulan Maret 2021 dengan besar sampel 29 orang dengan cara pengambilan sampel dalam penelitian dilakukan dengan non probability sampling yaitu dengan cara consecutive sampling.

\section{HASIL PENELITIAN}

Karakteristik reponden penelitian

Tabel 1. Karakteristik responden penelitian

\begin{tabular}{lll}
\hline Variabel & $\mathrm{n}(=29)$ & Persentase $(\%)$ \\
\hline Umur & & \\
\hline
\end{tabular}




\begin{tabular}{cccc}
\hline- & $<20$ tahun & 2 & 6,9 \\
$-\quad 20-35$ & 19 & 65,5 \\
& tahun & 8 & 27,6 \\
$-\quad>35$ tahun & & \\
\hline Paritas & & & \\
$-\quad 1$ & 4 & 13,8 \\
$-\quad 2$ & 9 & 31,0 \\
$-\quad 3$ & 10 & 34,5 \\
$-\quad 4$ & 4 & 13,8 \\
$-\quad 5$ & 2 & 6,9 \\
\hline Usia kehamilan & & \\
$-\quad$ Aterm & 29 & 100 \\
\hline Inisiasi menyusu & & 100 \\
dini & & 29 & 0 \\
- Ya & 0 & \\
- Tidak & &
\end{tabular}

Berdasarkan tabel 1 diketahui bahwa responden terbanyak berumur 20-35 tahun $(65,5 \%)$ dan paling sedikit umur $<20$ tahun $(6,9)$, paritas terbanyak adalah $3(34,5 \%)$ dan paling sedikit paritas $5(6,9 \%)$, semua responden melahirkan pada kehamilan aterm (100\%), dan semua responden melakukan inisiasi menyusu dini $(100 \%)$.

Tabel 2. Pelaksanaan inisiasi menyusu dini IMD)

\begin{tabular}{|c|c|c|}
\hline Variabel & $n(=29)$ & Persentase $(\%)$ \\
\hline \multicolumn{3}{|l|}{ Pelaksanaan IMD } \\
\hline - $\quad$ Antara 30 & 3 & 10,3 \\
\hline $\begin{array}{l}\text { menit s/d } 1 \\
\text { jam setelah } \\
\text { lahir }\end{array}$ & 26 & 89,7 \\
\hline $\begin{array}{ll}- & \text { Segera } \\
& \text { setelah lahir }\end{array}$ & & \\
\hline \multicolumn{3}{|l|}{ Lama IMD } \\
\hline - $\quad<30$ menit & 3 & 10,3 \\
\hline - $\quad$ Antara 30 & 20 & 69,0 \\
\hline $\begin{array}{l}\text { menit s/d } 1 \\
\text { jam }\end{array}$ & 6 & 20,7 \\
\hline$-\quad>1 \mathrm{jam}$ & & \\
\hline
\end{tabular}

Berdasarkan tabel 2 dapat dilihat bahwa pelaksanaan IMD paling banyak dilakukan segera setelah lahir $(89,7 \%)$ dan lama pelaksanaan IMD terbanyak antara 30 menit s/d 1 jam (69\%) namun ada juga yang melaksanakan IMD kurang dari 30 menit (10,3\%).

\section{PEMBAHASAN}

Hasil penelitian dengan gambaran pelaksanaan IMD mengamati langsung proses persalinan, dimana pengolahan data dengan distribusi frekuensi tanpa melakukan uji statistik. Dalam pembahasan ini penulis mengacu pada teori.

Berdasarkan hasil penelitian dari 29 responden yang berumur 20-35 tahun $(65,5 \%)$, paritas 3 yang terbanyak $(34,5 \%)$ rata-rata respon melahirkan aterm dan semua melakukan IMD (100\%).
Inisiasi Menyusu Dini adalah suatu rangkaian kegiatan dimana bayi segera setelah lahir yang sudah terpotong tali pusatnya secara naluri melakukan aktivitasaktivitas yang diakhiri dengan menemukan puting susu ibu kemudian menyusu pada satu jam pertama kelahiran.

Inisiasi Menyusui Dini (IMD) adalah memberikan Asi segera setelah bayi dilahirkan, biasanya dalam waktu 30 menit-1 jam pasca bayi dilahirkan. (Kemenkes, 2014).

Dengan IMD pada 1 jam pertama dapan meningkatkan potensi keberhasilan menyusui secara eksklusif selama 6 bulan dan dilanjutkan dengan makanan pendamping ASI sampai bayi berumur 2 tahun. ASI saja sudah dapat mencukupi semua kebutuhan bayi. Inisiasi menyusu dini dalam satu jam setelah kelahiran merupakan yang penting untuk mengurangi kematian bayi dan mengurangi banyak kematian neonatal. Menyelamatkan 1 juta bayi dimulai dengan satu tindakan, satu pesan dan satu dukungan yaitu dimulai Inisiasi Menyusu Dini dalam satu jam pertama kelahiran.

Pemerintah Indonesia telah menetapkan berbagai program untuk mendukung keberhasilan IMD diantaranya adalah program rumah sakit sayang ibu dan bayi (Menteri Kesehatan Republik Indonesia, 2008) dan sepuluh langkah keberhasilan menyusui yang ditetapkan oleh Menteri Pemberdayaan Perempuan \& Perlindungan Anak (Menteri Negara Pemberdayaan Perempuan \& Perlindungan Anak Republik Indonesia, 2010). Selain itu WHO telah memberikan rekomendasi kepada tenaga kesehatan agar melakukan konseling menyusui saat prenatal, postnatal, dan selama 24 bulan atau lebih. Konseling ini sedikitnya dilakukan selama enam kali, melalui tatap muka langsung, telepon, atau media lain (World Health Organization, 2018b).

Hasil penelitian Lestariningsih (2016) di ruang bersalin mendapati bahwa tidak semua pasien mendapatkan informasi dari tenaga kesehatan tentang IMD sebelum melahirkan. Penyuluhan yang diberikan tenaga kesehatan pada pasien inpartu biasanya dilihat terlebih dahulu pada kondisi ibu yang akan melahirkan, jika masih kooperatif penyuluhan pertama yang diberikan adalah tentang proses persalinan atau tehnik mengedan (Lestariningsih, 2016). Penelitian Damayanti (2016) menemukan bahwa pelaksanaan IMD belum maksimal masih sebesar $60 \%$ dilakukan oleh semua bidan (Damayanti, 2016).

Dalam penelitian ini menunjukkan bahwa petugas kesehatan mengetahui tentang tatalaksana IMD dan kapan IMD . dimana hasil penelitian ini dijumpai pelaksanaan IMD (100\%). Pada saat partus saat bayi lahir kita jumpai petugas kesehatan langsung melaksanakan IMD yaitu memberikan ASI segera setelah bayi lahir dalam waktu 30 menit-1 jam pasca bayi dilahirkan .

Pelaksanaan IMD tentunya membutuhkan kerjasama antara petugas kesehatan yang menolong persalinan dengan ibu dan keluarganya. Setiap tindakan medis tetap harus membutuhkan persetujuan dari keluarga, sebelum IMD dilakukan tetap harus 
dikonsultasikan kepada keluarga tentang manfaat dan pentingnya ASI.

\section{TATA LAKSANA IMD}

Berikut macam-macam pelaksanaan IMD

a. IMD yang kurang tepat (Roesli, 2012) :

1) Begitu lahir, bayi diletakkan diperut ibu yang sudah dialasi kain kering

2) Bayi segera dikeringkan dengan kain kering. Tali pusat dipotong, lalu diikat.

3) Bayi dibedong dengan selimut bayi karena takut kedinginan

4) Dalam keadaan dibedong, bayi diletakkan di dada ibu (tidak terjadi kontak dengan kulit ibu). Bayi dibiarkan di dada ibu untuk beberapa lama (10-15 menit) atau sampai tenaga kesehatan selesai menjahit perinium

5) Selanjutnya, bayi diangkat dan disusukan pada ibu dengan cara memasukkan puting susu ke mulut bayi.

6) Setelah itu, bayi dibawa ke kamar transisi atau kamar pemulihan untuk ditimbang, diukur, dicap, diazankan oleh ayah, diberi suntikan vitamin $\mathrm{K}$, dan kadang diberi tetes mata.

b) IMD secara umum (Roesli, 2012) :

1) Dianjurkan suami atau mendampingi keluarga persalinan

2) Disarankan untuk tidak atau mengurangi penggunaan obat kimiawi saat persalinan.

3) Bagitu bayi lahir, bayi diletakkan di perut ibu yang sudah dialasi kain kering

4) Keringkan seluruh tubuh bayi termasuk kepala secepatnya, kecuali kedua tangannya.

5) Tali pusat dipotong, lalu diikat

6) Zat lemak putih (vernix) yang melekat di tubuh bayi sebaiknya tidak dibersihkan karena zat ini membuat nyaman kulit bayi.

7) Tanpa dibedong, bayi langsung ditengkurapkan di dada atau perut ibu dengan kontak kulit bayi dan kulit ibu. Ibu dan bayi diselimuti bersama-sama. Jika perlu, bayi diberi topi untuk mengurangi pengeluaran panas dari kepalanya. Sering kita khawatir bayi kedinginan.

8) Bayi dibiarkan mencari puting susu ibu. Ibu dapat merangsang bayi dengan sentuhan lembut, tetapi tidak memaksakan bayi ke puting susu.

9) Ayah didukung agar membantu ibu untuk mengenali tanda- tanda atau perilaku bayi sebelum menyusu. Dukungan ayah akan meningkatkan rasa percaya diri ibu. Biarkan bayi dalam posisi kulit bersentuhan dengan kulit ibunya setidaknya selama satu jam, walaupun ia telah berhasil menyusu pertama sebelum satu jam. Jika belum menemukan puting payudara ibunya dalam waktu satu jam, biarkan kulit bayi tetap bersentuhan dengan kulit ibunya sampai berhasil menyusu pertama.

10) Bayi dipisahkan dari ibu untuk ditimbang, diukur, dan dicap setelah satu jam atau menyusu awal selesai. Prosedur yang invasif, misalnya suntikan vitamin $\mathrm{K}$ dan tetesan mata bayi dapat ditunda. Secara fisiologis kadar faktor koagulasi yang tergantung vitamin $\mathrm{K}$ dalam tali pusat sekitar $50 \%$ dan akan menurun dengan cepat mencapai titik terendah dalam 48-72 jam setelah kelahiran (Kemenkes RI, 2011).

11) Rawat gabung yaitu ibu dan bayi dirawat dalam satu kamar. Selama 24 jam ibu dan bayi tetap tidak dipisahkan dan bayi selalu dalam jangkauan ibu. Pemberian minuman prelaktal (cairan yang diberikan sebelum ASI keluar) dihindarkan.

\section{KESIMPULAN}

Penelitian ini dilakukan di BPM Kota Pematangsiantar dengan sampel sebesar 29 persalinan. Dari hasil penelitian diperoleh, bahwa responden terbanyak berumur $20-35$ tahun $(65,5 \%)$ dan paling sedikit umur $<20$ tahun $(6,9)$, paritas terbanyak adalah $3(34,5 \%)$ dan paling sedikit paritas $5(6,9 \%)$, semua responden melahirkan pada kehamilan aterm (100\%), dan semua responden melakukan inisiasi menyusu dini (100\%).

\section{DAFTAR PUSTAKA}

Abu Huraerah , 2008, Pengorganisasian dan Pengembangan Masyarakat, Model dan Strategi Pembangunan, Bandung : Humaniora

Andi, 2010. Mengolah Data Statistik Hasil Penelitian Dengan SPSS 17,, Edisi 1, C.V Andi Offset, Yogyakarta.

Azwar Saifuddin MA., 2013. Sikap dan Perilaku. Dalam: Sikap Manusia Teori dan Pengukurannya. 2nd ed. Yogyakarta: Pustaka Pelajar.

Edmond et all. (2006). Delayed Breastfeeding Initiation Increase Risk of Neonatal Mortality Rate. PubMed Central.

Kementrian Keseshatan RI, (2014). Pusat Data dan Informasi. Jakarta ASI Eksklusif.

Depkes RI. ( 2008). Paket Modul Kegiatan Inisiasi Menyusu Dini (IMD) dan ASI Eksklusif 6 Bulan. Jakarta. Kerjasama Pemerintah RI dengan UNICEF.

Roesli, U. (2009). Mengenal ASI Ekslusif. Seri 1. Jakarta: Puspa Swara. 
Roesli, U. (2009). Panduan Praktis Menyusui. Jakarta: Pustaka Bunda

Roesli, U. (2012). Panduan Inisiasi Menyusui Dini plus ASI eksklusif.

Jakarta: Pustaka Bunda.

Smith, E. R., Hurt, L., Chowdhury, R., Sinha, B., Fawzi, W., \& Edmond, K. M. (2017). Delayed breastfeeding initiation and infant survival: A systematic review and meta-analysis. PLoS ONE, 12(7), 1-16. https://doi.org/10.1371/journal.pone.0180722

UNICEF, \& WHO. (2018). Capture the Moment Early initiation of breastfeeding: The best start for every newborn. Unicef. Retrieved from https://data.unicef.org/topic/nutrition/infantand-young-child-

feeding/\%0Ahttps://www.unicef.org/publicat ions/files/UNICEF_WHO_Capture_the_mo ment_EIBF_2018.pdf

WHO \& UNICEF. (2018). Global Breastfeeding Scorecard, 2018. Enabling Women To Breastfeed Through Better Policies And Programmes. WHO/Unicef. Retrieved from http://www.who.int/nutrition/publications/inf antfeeding/global-bf-scorecard-

2018/en/\%0Ahttps://www.who.int/nutrition/p ublications/infantfeeding/global-bfscorecard-2018.pdf?ua $=1$ 